\title{
Why use of interventions targeting outdoor biting mosquitoes will be necessary to achieve malaria elimination
}

\author{
Nicodem James Govella ${ }^{1 *}$ and Heather Ferguson ${ }^{2}$ \\ Biomedical and Environmental Thematic Group, Ifakara Health Institute, Dar es Salaam, United Republic of Tanzania \\ College of Medical, Veterinary and Life Sciences, Boyd Orr Centre for Population and Ecosystem Health, University of Glasgow, Glasgow, UK \\ *Correspondence: govella@ihi.or.tz
}

Existing malaria vector control measures such as Long Lasting Insecticidal Nets (LLIN) and Indoor Residual Spraying (IRS) combined with Artemisinin Based Combination Therapy (ACT) drugs have significantly reduced the malaria burden in many parts of Africa (Battarai et al., 2007; Sharp et al., 2007a; Ceesay et al., 2008; O’Meara et al., 2008; WHO, 2009; Chizema-Kawesha et al., 2010; Ngomane and de Jager, 2012). The benefit of these interventions extends beyond the personal protection of the households that use them to protect entire communities by reducing either the infectiousness of blood stage parasites in human populations (Killeen et al., 2006a), or the abundance and survival of mosquito vectors (Killeen et al., 2007). It has been shown both theoretically (Killeen and Smith, 2007; Killeen et al., 2007) and in the course of operational control (Hawley et al., 2003; Klinkenberg et al., 2010) that significant community-wide reductions in transmission can be obtained even when intervention coverage levels are modest $(35-75 \%)$. However, it is unlikely that these packages of interventions of their own will be sufficient to achieve malaria elimination in the most endemic settings where transmission rates are extremely high (Gillies and Smith, 1960; White, 1969; Oyewole and Awolola, 2006; Bayoh et al., 2010; Van Bortel et al., 2010; Bugoro et al., 2011a; Reddy et al., 2011; Russell et al., 2011). Even should the considerable financial, logistic, and behavioral obstacles that currently limit attainment of $100 \%$ coverage be overcome (Vanden et al., 2010; Larson et al., 2012), the combined use of effective anti-malarial drugs and these vector control interventions are not predicted to be sufficient for elimination in these settings (Killeen et al., 2000; Griffin et al., 2010) Because they do not cover the full spectrum of all locations where mosquito exposure occurs, and even if only a small percentage of mosquitoes remain and bite outside, their existence could be enough to prevent the transition from very low to zero transmission.

The World Health Organization (WHO) defines malaria elimination as meaning the permanent reduction "to zero incidence of locally contracted cases, although imported cases will continue to occur and continued interventions measures are required" (WHO, 2008b). Achieving this goal will require full understanding of where and when persons are most exposed to the bites of mosquito vectors in order to target interventions where they can achieve maximum impact. While elimination is possible in some settings with low malaria transmission intensity (WHO, 2009; Griffin et al., 2010), and where the dominant vectors exhibit the stereotypical behaviors of biting indoors and late at night where they can be targeted by LLIN and/or IRS (Mabaso et al., 2004; Sharp et al., 2007b; John et al., 2009; WHO, 2009), it is unlikely that these methods will be sufficient to push prevalence below the WHO-defined pre-elimination threshold ( $<1$ case/1000 population/year) in areas of high transmission (Molineaux and Gramiccia, 1980; Kleinschmeidt et al., 2009; Russell et al., 2010) and where the majority of human exposure to transmitting mosquitoes occurs outside human dwellings to which most current interventions are restricted (Taylor, 1975; Pates and Curtis, 2005; Tirados et al., 2005; Oyewole and Awolola, 2006; Geissbühler et al., 2007; Griffin et al., 2010; Van Bortel et al., 2010; Bugoro et al., 2011a; Yohannes and Boelee, 2012). To date, probably the most comprehensive attempt to achieve local elimination within an endemic region of Africa was made in the Garki region of northern Nigeria in the 1970's (Molineaux and Gramiccia, 1980; WHO, 2008b). Before initiating this campaign, malaria transmission within this region was extremely high (example as indexed by an estimated annual entomologic inoculation rate, EIR of 20-120 infectious mosquito bites per person per year). During the elimination program which ran from 1972 to 1973 , near complete coverage of all households (97-99\%) with propoxur-based IRS combined with mass drug administration of the anti-malarials sulfalene and pyrimethamine (73-92\% coverage) was attained throughout the study area. Although these intense efforts led to a drastic reduction in malaria prevalence within the region from 70 to $1 \%$, the threshold for local elimination was not even approached (Molineaux and Gramiccia, 1980). A critical factor in the failure of elimination was incomplete suppression of vector populations due to the existence of low level outdoor-feeding (exophagy) and resting (exophily) behaviors within a small proportion of locally important vector populations (Molineaux and Gramiccia, 1980). This small proportion of mosquitoes with atypical behaviors was sufficient to prevent elimination even across a short period of time in which the potential for insecticide resistance was not recorded. Furthermore, by preventing the rapid achievement of elimination, the existence of these vectors may enhance the likelihood and spread of Insecticide Resistance by necessitating the continued application of high dose formulations over longer periods of time.

While historically transmission in much of Africa has been dominated by vector species that primarily feed and rest indoors where they can be efficiently targeted with domestic insecticides (Gillies and DeMeillon, 1968; White, 1974; Gillies and Coetzee, 1987), there is growing evidence from across the continent that the widespread use of LLINs and IRS is driving vector species composition toward those with more flexible behaviors (Braimah et al., 2005; Pates and Curtis, 2005; Tirados et al., 2005; Antonio-Nkondjio et al., 2006; Oyewole and Awolola, 2006; Geissbühler et al., 2007; Bayoh et al., 2010; Reddy 
et al., 2011; Russell et al., 2011). For instance Anopheles gambiense sensu stricto has been historically viewed as the most significant vector of malaria in Africa (Gillies and DeMeillon, 1968; White, 1974; Gillies and Coetzee, 1987; Kiszewski et al., 2004). However in the wake of the widespread deployment of domestic insecticidal interventions, this species is in significant decline in many areas; with the majority of remaining transmission now being dominated by An. arabiensis (Braimah et al., 2005; Tirados et al., 2005; Bayoh et al., 2010; Russell et al., 2011); a closely related sibling species that can exhibit much more flexible behaviors including biting people and resting outdoors, and switching their biting between humans and common domestic animals such as cattle (Gillies and DeMeillon, 1968; White, 1974; Gillies and Coetzee, 1987; Tirados et al., 2005).

Even low levels of exophagy, exophily, or zoophagy (Table 1) may substantially attenuate the impact of LLIN and IRS because this allows mosquitoes to obtain blood while avoiding fatal contact with insecticides (Smith and Gillies, 1960; Taylor, 1975; Molineaux and Gramiccia, 1980; Pates and Curtis, 2005; Geissbühler et al., 2007; Killeen and Smith, 2007; Govella et al., 2010; Bugoro et al., 2011a). Furthermore, the deployment of insecticides inside houses is likely to place strong selection on even highly endophilic species to switch their behaviors, which could not only prevent the achievement of elimination but undermine the continued effectiveness of these interventions (White, 1974; Pates and Curtis, 2005; Van Bortel et al., 2010; Bugoro et al., 2011a). For example in Bioko Island, Equatorial Guinea, $A n$. gambiae s.s. were historically documented to feed almost entirely indoors (Molina et al., 1996). However, following initiation of mass coverage campaigns with indoorinsecticide based interventions, the behavior of this vector species has switched to an almost 50:50 split between indoor and outdoor biting (Reddy et al., 2011).
With the shift in policy from targeted to universal distribution of LLINs to each sleeping space in many parts of Africa (Teklehaimanot et al., 2007; WHO, 2008a; Kilian et al., 2010), it has been increasingly observed that mosquitoes can re-adjust their biting activity so that much of it occurs outdoors and before bed time across different settings (Rubio-Palis and Curtis, 1992; Trung et al., 2005; Bayoh et al., 2010; Van Bortel et al., 2010; Bugoro et al., 2011a,b; Reddy et al., 2011; Russell et al., 2011). This is due to the fact that indoor biting species (Smith and Gillies, 1960; Gillies and Furlong, 1964; Gillies and DeMeillon, 1968; Pates and Curtis, 2005; Killeen et al., 2006b) and subpopulations (Coluzzi et al., 1979; Molineaux and Gramiccia, 1980; Bendesky and Bargmann, 2011) will be more affected, leaving predominantly the outdoor-feeding, "early biting" residual populations and individuals (Gillies and Smith, 1960; Taylor, 1975; Bayoh et al., 2010; Bugoro et al., 2011a,b; Russell et al., 2011) to maintain residual transmission. Evidence from the previous Global Malaria Elimination campaign (1950s) suggests this is not only a recent phenomenon. Following the widespread implementation of IRS in the South Pare Region of Tanzania (19551959), the highly endophilic vector $A n$. funestus disappeared leaving only an $A n$. gambiae s.l. population which exhibited extremely exophilic behavior (Smith and Gillies, 1960). Similarly, An. funestus was also replaced by the highly zoophagic and exophilic species An. rivulorum and/or An. parensis on at least three distinct occasions following the implementation of IRS in South Africa, Kenya, and Tanzania (Gillies and Smith, 1960; Gillies and Furlong, 1964). Note that not all of the mosquito vector behavioral shifts mentioned above may necessarily hinder malaria control. For example, while a shift in vector behavior to biting people outside or before bedtime would clearly allow them to evade control, the impacts of others such as increased zoophagy are not clear cut. For example, while

\section{Table 1 | Definition of mosquito behavioral choices.}

Exophagy: is a tendency for mosquitoes to prefer biting outside

Endophagy: is a tendency for mosquitoes to prefer biting indoor

Exophily: is a tendency for mosquitoes to prefer resting outside

Endophily: is a tendency for mosquitoes to prefer resting indoor

Zoophagy: is a tendency for mosquitoes to prefer feeding on animal hosts

shifting their behavior from biting people to livestock would allow vectors to avoid insecticides, but it would concurrently prevent them from becoming infected or transmitting. Thus if interventions prompted increased zoophily in vector populations, it could actually help enhance control and prospects for elimination if it resulted in a long term, stable shift away from biting humans, and did not just provide them with a short term strategy to maintain their populations in the face of insecticide use, before later returning to feeding on humans when insecticide coverage dropped and/or resistance emerged (see reference Ferguson et al., 2010 for more review).

More recently, the long term use $(\sim 10$ years $)$ of ITNs at high coverage in western Kenya and south eastern Tanzania has been accompanied by a substantial shift in malaria vector species composition as manifested by the progressive diminishment of the importance of the highly endophagic/endophilic An. gambiae s.s. (Bayoh et al., 2010; Russell et al., 2011). Examples of similar phenomenon have also been observed outside Africa. In the Solomon islands, for example, intense IRS campaigns conducted in the 1960 s appeared to have eliminated the major vectors $A n$. punctulatus and An. koliensis which predominantly rest indoors, but recent programs combining ITNs and IRS have had negligible impact upon human biting rates because the remaining, current primary vector species $A n$. farauti feeds and rests predominantly outdoors (Bugoro et al., 2011a). Similar phenomena may be in Asia where human exposure to mosquito bites predominantly occurs outside houses and before bed time (Van Bortel et al., 2010).

\section{CONCLUSION}

As mosquito feeding behaviors critically determine the effectiveness of most current front-line vector control intervention measures, there is a critical need to establish systematic monitoring of these phenotypes and how they are changing as part of the drive toward elimination. Furthermore, although malaria control experts must undoubtedly continue to deliver interventions that tackle indoor transmission in Africa, a considerable investment of resources in methods that target mosquitoes outside of houses and before sleeping hours is urgently required to sustain existing levels of malaria control and 
make further inroads to achieve elimination (Ferguson et al., 2010; Griffin et al., 2010). To date, there is no intervention that specifically targets outdoor biting mosquitoes in common use throughout Africa. The only currently operational approach that could provide these benefits is larviciding (Killeen et al., 2002a, 2006c; Fillinger et al., 2008, 2009; Worrall and Fillinger, 2011), which by killing larval mosquitoes in their aquatic habitats may be assumed to efficiently target both the endophilic- and exophilic proportion of vector populations. Recent analysis suggests this method may be cost effective and practical in a much wider range of ecological settings than previously considered (Worrall and Fillinger, 2011). Even so, there is unlikely to be one "silver-bullet" approach to controlling outdoor biting mosquitoes and there is an urgent need to develop and assess a variety of complementary measures. Encouragingly there has been upsurge in interest in such methods in recent years, with progress being made toward assessing the potential use of large-scale spatial repellents (Moore et al., 2007), the application of insecticides to alternative hosts such as livestock (Rowland et al., 2001), the development of odor-baited traps for use outdoors (Knols et al., 2010; Okumu et al., 2010), the enhancement, and expansion of larvicidebased approaches (Soper and Wilson, 1943; Shousha, 1948; Kitron and Spielman, 1989; Killeen et al., 2002a,b; Fillinger and Lindsay, 2006; Gu and Novak, 2006; Gu et al., 2006; Fillinger et al., 2008, 2009; Chaki et al., 2009) and environmental management (WHO, 1982; Castro et al., 2004, 2009, 2010).

While malaria control experts must not stop to deliver interventions that tackle indoor transmission, we argue that further sustained investment not only into systematic monitoring of mosquito behavioral phenotypes and how they are changing but also on rapid case detection and treatment and substantial investment into the development and translation of outdoor-based interventions into wide-scale use must be prioritized a fundamental strategy for achieving elimination in mainland Africa.

\section{ACKNOWLEDGMENTS}

We thank the Bill and Melinda Gates Foundation through the Malaria Transmission Consortium (Award number 45114), coordinated by Dr Neil Lobo and Prof. Frank Collins at Notre Dame
University, and the European Union through African Vector Control: New tool (Award number 265660) coordinated by Dr. Eve Worrall and Prof. Hilary Ranson at Liverpool School of Tropical Medicine for provision of financial support. We also appreciate the contributions by Dr. Gerry Killeen.

\section{REFERENCES}

Antonio-Nkondjio, C., Kerah, C. H., Simard, F., AwonoAmbene, P., Chouaibou, M., Tchuinkam, T., and Fontenille, D. (2006). Complexity of the malaria vectorial system in Cameroon: contribution of secondary vectors to malaria transmission. J. Med. Entomol. 43, 1215-1221.

Battarai, A., Ali, A. S., Kachur, S. P., Martensson, A., Abbas, A. K., Khatib, R., Al-mafazy, A., Ramsan, M., Rottlant, G., Gerstenmaier, J. F., Molteni, F., Abdulla, S., Montgomery, S. M., Kaneko, A., and Bjorkman, A. (2007). Impact of artemisinin-based combination therapy and insecticide-treated nets on malaria burden in Zanzibar. PLoS Med. 4, e309. doi: 10.1371/ journal.pmed.0040309

Bayoh, M. N., Mathias, D. K., Odiere, M. R., Mutuku, F. M., Kamau, L., Gimnig, J. E., Vulule, J. M., Hawley, W. A., Hamel, M. J., and Walker, E. D. (2010). Anopheles gambiae: historical population decline associated with regional distribution of insecticide-treated bed nets in Western Nyanza Province, Kenya. Malar. J. 9, 62.

Bendesky, A., and Bargmann, C. I. (2011). Genetic contributions to behavioural diversity at the geneenvironmental interface. Nat. Rev. 12, 809.

Braimah, N., Drakeley, C., Kweka, E., Mosha, F. W., Helinski, M., Pates, H., Maxwell, C. A., Massawe, T., Kenward, M. G., and Curtis, C. (2005). Tests of bednet traps (Mbita traps) for monitoring mosquito populations and time of biting in Tanzania and possible impact of prolonged ITN use. Int. J. Trop. Insect Sci. $25,208-213$.

Bugoro, H., Cooper, R. D., Butafa, C., Iroofa, C., Mackenzie, C., Chen, C. C., and Russell, T. L. (2011a). Bionomics of the malaria vector Anopheles farauti in Temotu Province, Solomon Islands: issues for malaria elimination. Malar. J. 10, 133.

Bugoro, H., Iroofa, C., Mackenzie, D. O., Apairamo, A., Hevalao, W., Corcoran, S., Bobogare, A., Beebe, N.W., Russell, T. L., Chen, C. C., and Cooper, R. D. (2011b). Changes in vector species composition and current vector biology and behaviour will favour malaria elimination in Santa Isabel Province, Solomon Island. Malar. J. 10, 287.

Castro, M. C., Kanamori, S., Kannady, K., Mkude, S., Killeen, G. F., and Fillinger, U. (2010). The importance of drains for the larval development of lymphatic filariasis and malaria vectors in Dar es salaam, United Republic of Tanzania. PLoS Negl. Trop. Dis. 4, e693. doi: 10.1371/journal.pntd.0000693

Castro, M. C., Tsuruta, A., Kanamori, S., Kannady, K., and Mkude, S. (2009). Community-based environmental management for malaria control: evidence from a small-scale intervention in Dar es Salaam, Tanzania. Malar. J. 8, 57.

Castro, M. C., Yamagata, Y., Mtasiwa, D., Tanner, M., Utzinger, J., Keiser, J., and Singer, B.H. (2004). Integrated urban malaria control: a case study in Dar es Salaam, Tanzania. Am. J. Trop. Med.Hyg.71(Suppl.2), 103-117.
Ceesay, S., Casals-Pascual, C., Erskine, J., Anya, S. E., Duah, N. O., Fulford, A. J. C., Sesay, S. S. S., Abubakar, I., Dunyo, S., Sey, O., Palmer, A., Fofana, M., Corrah, T., Bojang, K. A., Whittle, H. C., Greenwood, B. M., and Conyway, D. J. (2008). Changes in malaria indices between 1999 and 2007 in The Gambia: a retrospective analysis. Lancet 372, 1545-1554.

Chaki, P. P., Govella, N. J., Shoo, B., Hemed, A., Tanner, M., Fillinger, U., and Killeen, G. F. (2009). Achieving high coverage of larval-stage mosquito surveillance: challenges for a community-based mosquito control programme in urban Dar es Salaam, Tanzania. Malar. J. 8,311 .

Chizema-Kawesha, E., Miller, J. M., Steketee, R. W., Mukonka, V. M., Mukuka, C., Mohamed, A. D., Miti, S. K., and Campbell, C. C. (2010). Scaling up malaria control in Zambia: progress and impact 2005-2008. Am. J. Trop. Med. Hyg. 83, 480-488.

Coluzzi, M., Sebatin, A., Petrarca, V., and Di Deco, M. A. (1979). Chromosomal differentiation and adaptation to human environments in the Anopheles gambiae complex. Trans. R. Soc. Trop. Med. Hyg. 72, 483-498.

Ferguson, H. M., Dornhaus, A., Beeche, A., Borgemeister, C., Gottlieb, M., Mulla, M. S., Gimnig, J. E., Fish, D., and Killeen, G. F. (2010). Ecology: a prerequisite for malaria elimination and eradication. PLoS Med. 7 , e1000303. doi: 10.1371/journal.pmed.1000303

Fillinger, U., Kannady, K., William, G., Vanek, M. J., Dongus, S., Nyika, D., Geissbuhler, Y., Chaki, P. P., Govella, N. J., Mathenge, E. M., Singer, B. H., Mshinda, H., Lindsay, S. W., Tanner, M., Mtasiwa, D., Castro, M. C., and Killeen, G. F. (2008).A tool box for operational mosquito larval control; preliminary results and early lessons from the Urban Malaria Control Programme in Dar es Salaam. Malar. J. 7, 20.

Fillinger, U., and Lindsay, S. W. (2006). Suppression of exposure to malaria vectors by an order of magnitude using microbial larvicides in rural Kenya. Trop. Med. Int. Health 11, 11.

Fillinger, U., Ndenga, B., Githeko, A., and Lindsay, S. W. (2009). Integrated malaria vector control with microbial larvicide and insecticide-treated nets in western Kenya: a controlled trial. Bull. World Health Organ. 87, 655-665.

Geissbühler, Y., Chaki, P., Emidi, B., Govella, N. J., Shirima, R., Mayagaya, V., Mtasiwa, D., Mshinda, H., Fillinger, U., Lindsay, S. W., Kannady, K., Caldas de Castro, M., Tanner, M., and Killeen, G. F. (2007). Interdependence of domestic malaria prevention measures and mosquito-human interactions in urban Dar es Salaam, Tanzania. Malar. J. 6, 126.

Gillies, M. T., and Coetzee, M. (1987). A Supplement to the Anophelinae of Africa South of the Sahara (Afrotropical Region). Johannesburg: South African Medical Research Institute.

Gillies, M.T., and DeMeillon, B. (1968). The Anophelinae of Africa South of the Sahara (Ethiopian Zoogeographical Region). Johannesburg: South African Institute for Medical Research.

Gillies, M. T., and Furlong, M. (1964). An investigation into behaviour of Anopheles parensis Gillies at Malindi on coast of Kenya. Bull. Entomol. Res. 55, 1-16.

Gillies, M. T., and Smith, A. (1960). Effect of a residual house spraying campaign on species balance in Anopheles funestus group: the replacement of Anopheles funestus Giles with Anopheles rivulorum Leeson. Bull. Entomol. Res. 51, 248-252.

Govella, N. J., Okumu, F. O., and Killeen, G. F. (2010). Insecticide-treated nets can reduce malaria 
transmission by mosquitoes which feed outdoors. Am. J. Trop. Med. Hyg. 82, 415-419.

Griffin, J. T., Hollingsworth, T. D., Okell, L. C., Churcher, T. S., White, M., Hinsley, W., Bousema, T., Drakeley, C. J., Ferguson, N. M., Basanez, M., and Ghani, A. C. (2010). Reducing Plasmodium falciparum malaria transmission in Africa: a model-based evaluation of intervention strategies. PLoS Med. 7, e1000324. doi: 10.1371/journal.pmed.1000324

$\mathrm{Gu}, \mathrm{W}$., and Novak, R. J. (2006). Letters to the editor in reply. Am. J. Trop. Med. Hyg. 74, 519-520.

Gu, W., Regens, J. L., Beier, J. C., and Novak, R. J. (2006). Source reduction of mosquito larval habitats has unexpected consequences on malaria transmission. Proc. Natl. Acad. Sci. U.S.A. 103, 17560-17563.

Hawley, W. A., Phillips-Howard, P. A., Terkuile, F. O., Terlouw, D. J., Kolczak, M. S., and Hightower, A. W. (2003). Community-wide effects of permethrintreated bed nets on child mortality and malaria morbidity in western Kenya. Am. J. Trop. Med. Hyg. 68(Suppl. 4), 121-127.

John, C. C., Riedesel, M. A., Magak, N. G., Lindblade, K. A., Menage, D. M., Hodges, J. S., Vulule, J. M., and Akhwale, W. (2009). Possible interruption of malaria transmission, highland Kenya 2007-2008. Emerging Infect. Dis. 15, 1917-1924.

Kilian, A., Boulay, M., Koenker, H., and Lynch, M. (2010). How many mosquito nets are needed to achieve universal coverage? recommendation for quantification and allocation of long-lasting insecticidal nets for mass compaigns. Malar. J. 9, 330.

Killeen, G. F., Fillinger, U., Kiche, I., Gouagna, L. C., and Knols, B. G. J. (2002a). Eradication of Anopheles gambiae from Brazil: lessons for malaria control in Africa? Lancet. Infect. Dis. 2, 618-627.

Killeen, G. F., Fillinger, U., and Knols, B. G. J. (2002b). Advantages of larval control for African malaria vectors: low mobility and behavioural responsiveness of immature mosquito stages allow high effective coverage. Malar. J. 1, 8.

Killeen, G. F., McKenzie, F. E., Foy, B. D., Schieffelin, C., Billingsley, P. F., and Beier, J. C. (2000). The potential impacts of integrated malaria transmission control on entomologic inoculation rate in highly endemic areas. Am. J. Trop. Med. Hygn. 62, 545-551.

Killeen, G. F., Ross, A., and Smith, T. A. (2006a). Infectiousness of malaria-endemic human populations to vector mosquitoes. Am. J. Trop. Med. Hyg. 75, 38-45.

Killeen, G. F., Kihonda, J., Lyimo, E., Oketch, F. R., Kotas, M. E., Mathenge, E., Schellenberg, J. A., Lengeler, C., Smith, T. A., and Drakeley, C. J. (2006b). Quantifying behavioural interactions between humans and mosquitoes: evaluating the protective efficacy of insecticidal nets against malaria transmission in rural Tanzania. BMC Infect. Dis. 6, 161. doi: 10.1186/1471-2334-6-161

Killeen, G. F., Tanner, M., Mukabana, W. R., Kalongolela, M. S., Kannady, K., Lindsay, S. W., Fillinger, U., and Castro, M. C. (2006c). Habitat targeting for controlling aquatic stages of malaria vectors in Africa. Am. J. Trop. Med. Hyg. 74, 517-518.

Killeen, G. F., and Smith, T.A. (2007). Exploring the contributions of bed nets, cattle, insecticides and excitorepellency to malaria control: a deterministic model of mosquito host-seeking behaviour and mortality. Trans. R. Soc. Trop. Med. Hyg. 101, 867-880.

Killeen, G. F., Smith, T. A., Ferguson, H. M., Mshinda, H., Abdulla, S., Lengeler, C., and Kachur, S. P. (2007).
Preventing childhood malaria in Africa by protecting adults from mosquitoes with insecticide-treated nets. PLoS Med. 4, e229. doi: 10.1371/journal. pmed.0040229

Kiszewski, A., Mellinger, A., Spielman, A., Malaney, P., Sachs, S. E., and Sachs, J. (2004). A global index representing the stability of malaria transmission. Am. J. Trop. Med. Hyg. 70, 486-498.

Kitron, U., and Spielman, A. (1989). Suppression of transmission of malaria through source reduction: antianopheline measures applied in Israel, the United States, and Italy. Rev. Infect. Dis. 11, 391-406.

Kleinschmeidt, I., Schwabe, C., Benavente, L., Torrez, M., and Ridl, F. C. (2009). Marked increase in child survival after four years of intensive malaria control. Am. J. Trop. Med. Hyg. 80, 883-888.

Klinkenberg, E., Kwabena, A. O., McCall, P. J., Wilson, M. D., Bates, I., Verhoeff, F. H., Barnish, G., and Donnelly, M. J. (2010). Cohort trial reveals community impact of insecticide-treated nets on malariometric indices in urban Ghana. Trans. R. Soc. Trop. Med. Hyg. 104, 496-503.

Knols, B. G. J., Bukhari, T., and Farenhorst, M. (2010). Entomopathogenic fungi as the next-generation control agents against malaria mosquitoes. Future Microbiol. 5, 339-341.

Larson, P. S., Mathanga, D. P., Campbell, C. H., and Wilson, M. L. (2012). Distance to health services influences insecticide-treated nets possession and use among six to 59 month-old children in Malawi. Malar. J. 11, 18.

Mabaso, M. L., Sharp, B., and Lengeler, C. (2004). Historical review of malarial control in southern African with emphasis on the use of indoor residual house-spraying. Trop. Med. Int. Health 9, 846-856.

Molina, R., Benito, A., Blanca, F., Roche, J., Otunga, B. and Alvar, J. (1996). The Anophelines of Equatorial Guinea: ethology and susceptibility studies. Res. Rev. Parasitol. 56, 105-110.

Molineaux, L., and Gramiccia, G. (1980). The Garki Project. Geneva: World Health Organisation, 311.

Moore, S. J., Darling, S. T., Sihuincha, M., Padilla, N., and Devine, G. J. (2007). A low-cost repellents for malaria vectors in the Americas: results of two field trials in Guatemala and Peru. Malar. J. 6, 101.

Ngomane, L., and de Jager, C. (2012). Changes in malaria morbidity and mortality in Mpumalanga Province, South Africa (2001-2009): a retrospective study. Malar. J. 11, 19.

Okumu, F. O., Madumla, E. P., John, A. N., Lwetoijera, D. W., and Sumaye, R. D. (2010). Attracting, trapping and killing disease-transmitting mosquitoes using odor-baited stations-the Ifakara Odor-Baited Stations. Parasit. Vectors $3,12$.

O'Meara, W. P., Bejon, P., Mwangi, T. W., Okiro, E. A., Peshu, N., Snow, R. W., Newton, C. R. J.C., and Marsh, K. (2008). Effect of a fall in malaria transmission on morbidity and mortality in Kilifi, Kenya. Lancet 372 , 1555-1562.

Oyewole, I. O., and Awolola, T.S. (2006). Impact of urbanization on bionomics and distribution of malaria vectors in Lagos, southwestern Nigeria. J. Vector Borne Dis. 43, 173-178.

Pates, H., and Curtis, C. (2005). Mosquito behavior and vector control. Annu. Rev. Entomol. 50, 53-70.

Reddy, M. R., Overgaard, H. J., Abaga, S., Reddy, V. P., Caccone, A., Kiszewski, A. E., and Slotman, M. A. (2011). Outdoor host seeking behaviour of Anopheles gambiae mosquitoes following initiation of malaria vector control on Bioko Island, Equatorial Guinea. Malar. J. 10, 154.

Rowland, M., Durrani, N., Kenward, M., Mohammed, N., Urahman, H., and Hewitt, S. (2001). Control of malaria in Pakistan by applying deltamethrin insecticide to cattle: a community-randomised trial. Lancet 357, 1837-1841.

Rubio-Palis, Y., and Curtis, C. F. (1992). Biting and resting behaviour of Anophelines in western Venezuela and implications for control of malaria transmission. Med. Vet. Entomol. 6, 325-334.

Russell, T. L., Govella, N. J., Azizii, S., Drakeley, C. J., Kachur, S. P., and Killeen, G. F. (2011). Increased proportions of outdoor feeding among residual malaria vector populations following increased use of insecticide-treated nets in rural Tanzania. Malar. J. 10,80 .

Russell, T. L., Lwetoijera, D. W., Maliti, D., Chipwaza, B., Kihonda, J., Charlwood, J. D., Smith, T. A., Lengeler C., Mwanyangala, M. A., Nathan, R., Knols, B. G. J., Takken, W., and Killeen, G. F. (2010). Impact of promoting longer-lasting insecticide treatment of bed nets upon malaria transmission in a rural Tanzanian setting with pre-existing high coverage of untreated nets. Malar. J. 9, 187.

Sharp, B. L., Kleinschmidt, I., Streat, E., Maharaj, R., Barnes, K. I., Durrheim, D. N., Ridl, F. C., Morris, N., Seocharan, I., Kunene, S., La Grange, J. .., Mthembu, J. D., Maartens, F., Martin, C. L., and Barreto, A. (2007a). Seven years of regional malaria control collaboration - Mozambique, South Africa, and Swaziland. Am. J. Trop. Med. Hyg. 76, 42-47.

Sharp, B. L., Ridl, F. C., Govender, D., Kuklinski, J., and Kleinschmidt, I. (2007b). Malaria vector control by indoor residual insecticide spraying on the tropical island of Bioko, Equatorial Guinea. Malar. J. 6, 52.

Shousha, A. T. (1948). Species-eradication. the eradication of Anopheles gambiae from Upper Egypt, 1942 1945. Bull. World Health Organ. 1, 309-353.

Smith, A., and Gillies, M. T. (1960). Report of the PareTaveta Malaria Scheme 1954-1959. Dar es Salaam: East African Institute of Malaria and Vector-Borne Diseases.

Soper, F. L., and Wilson, D. B. (1943). Anopheles gambiae in Brazil: 1930 to 1940. New York: The Rockefeller Foundation.

Taylor, B. (1975). Changes in feeding behaviour on malaria vector, Anopheles farauti Lav., following use of DDT a residual spray in houses in the British Solomon Island Protectoriate. Trans. R. Entomol. Soc. Lond. 127, 277-292.

Teklehaimanot, A., McCord, G. C., and Sachs, J.D. (2007). Scaling up malaria control in Africa: an economic and epidemiological assessment. Am. J. Trop. Med. Hyg. 77, 138-144.

Tirados, I., Costantini, C., Gibson, G., and Torr, S. J. (2005). Blood-feeding behaviour of the malarial mosquito Anopheles arabiensis: implications for malaria control. Med. Vet. Entomol. 20, 425-427.

Trung, H. D., Bortel, W. V., Sochantha, T., Keokenchanh, K., and Briet, O.J.T. (2005). Behavioural heterogeneity of Anopheles species in ecologically different localities in southeast Asia: a challenge for vector control. Trop. Med. Int. Health 10, 251-262.

Van Bortel, W., Dinh Trung, H., Huxan Hoi, L., Van Ham, N., Van Chut, N., Dinh Luu, N., Roelants, P., Denis, L., Speybroeck, N., D'Alessandro, U., and Coosemans, 
M. (2010). Malaria transmission and vector behaviour in a forested malaria focus in central Vietnam and implications for vector control. Malar. J. 9, 373.

Vanden, J. L., Thwing, J., Wolkon, A., Kulkarni, M. A., Manya, A., Erskine, M., Hightower, A., and Slutsker, L. (2010). Assessing bed net use and non-use after long-lasting insecticidal net distribution: a simple framework to guide programmatic strategies. Malar. J. 9, 133.

White, G. B. (1969) Blood Feeding Habits of Malaria Vector Mosquitoes in the South Pare District of Tanzania 10 Years After Cessation of Dieldrin Residual Spraying Campain. Geneva: WHO.

White, G. B. (1974). Anopheles gambiae complex and disease transmission in Africa. Trans. R. Soc. Trop. Med. Hyg. 68, 279-301.
WHO. (2008a). RollBackMalariaPartnership: The Global Malaria Action Plan for a Malaria-Free World. Geneva: World Health Organization.

WHO. (2008b). Global Malaria Control and Elimination: Report of a Technical Review. Geneva: World Health Organization.

WHO. (2009). World Malaria Report. Geneva: World Health Organization.

WHO. (ed.). (1982). Manual on Environmental Management for Mosquito Control. Geneva: World Health Organisation.

Worrall, E., and Fillinger, U. (2011). Large-scale use of mosquito larval source management for malaria control in Africa: a cost analysis. Malar. J. 10, 338.

Yohannes, M., and Boelee, E. (2012). Early biting rhythm in the afro-tropical vector of malaria, Anopheles arabiensis, and challenges for its control in Ethiopia. Med. Vet. Entomol. 26, 103-105.

Received: 01 November 2011; accepted: 22 May 2012; published online: 12 June 2012.

Citation: Govella NJ and Ferguson H (2012) Why use of interventions targeting outdoor biting mosquitoes will be necessary to achieve malaria elimination. Front. Physio. 3:199. doi: 10.3389/fphys.2012.00199

This article was submitted to Frontiers in Systems Biology, a specialty of Frontiers in Physiology.

Copyright $@ 2012$ Govella and Ferguson. This is anopen-access article distributed under the terms of the Creative Commons Attribution Non Commercial License, which permits noncommercial use, distribution, and reproduction in other forums, provided the original authors and source are credited. 